\title{
The Role of Glucocorticoids in the
}

\section{Regulation of Thyroid Function in Man}

\author{
John T. Nicoloff, Delbert A. Fisher, and Milo D. Appleman, Jr. \\ From the University of Southern California School of Medicine, UCLA School \\ of Medicine, and the Los Angeles County-USC Medical Center, \\ Los Angeles, California 90033
}

\begin{abstract}
A BSTRACT The diurnal variation in thyroidal iodine release previously observed in euthyroid subjects appears to correlate with variations in serum immunoassayable thyrotropin (TSH). The hypothesis is advanced that this diurnal rhythm seems to be primarily regulated by a negative feedback action of circulating hydrocortisone. The administration of maintenance doses of hydrocortisone to patients with primary adrenal insufficiency and pharmacological doses to euthyroid subjects was accompanied by an acute suppression in both thyroidal iodine release and serum TSH values. An escape from glucocorticoid suppression was observed to occur in 2 or 3 days with the resumption of a nearnormal thyroidal iodine release rate but was accompanied by a dampening or absence of the normal diurnal rhythm. Withdrawal of pharmacological doses of glucocorticoids in euthyroid subjects and maintenance doses in primary hypoadrenal patients was accompanied by transient stimulation of both serum TSH and thyroidal iodine release values. The study of a patient before and after cryohypophysectomy indicated that the rebound response in thyroid release after steroid withdrawal may be a useful testing procedure to indirectly assess the hypothalamicpituitary reserve capacity of TSH.
\end{abstract}

\section{INTRODUCTION}

The action of glucocorticoids in altering thyroid function has been both an area of considerable investigative interest and confusion. Ingbar and Freinkel reviewing this subject in 1956 concluded that the "weight of evidence" indicated that corticotropin (ACTH) and cortisone probably transiently suppress thyrotropin (TSH) release at the hypothalamic level. But these authors were

This work was presented in part at the 51st Endocrine Society Meeting, 28 June 1969.

Received for publication 19 May 1970 and in revised form 22 June 1970. quick to add that they did not support this concept with any "profound conviction" and that future investigation most certainly was essential to clarify the subject (1). Subsequently, Ducommun, Sakiz, and Guillemin have reported in the rat a reciprocal relationship between TSH and ACTH secretion in response to cold and other extroceptive stimuli (2). Retiene, Zimmerman, Schindler, Neuenschwander, and Lipscomb also have observed a reciprocal relationship between ACTH and TSH secretion while studying the spontaneous endocrine rhythms in the rat (3). Recently, Wilber and Utiger described both in man and in the rat an acute suppression of TSH secretion which occurs after the administration of pharmacological doses of glucocorticoids and a rebound in TSH release after withdrawal (4) of glucocorticoids. It is the purpose of this study to extend these observations, to present evidence concerning the role of glucocorticoids in the regulation of normal thyroid function in man, and to demonstrate that withdrawal from glucocorticoid administration may be a useful testing method for assessing TSH reserve capacity.

\section{METHODS}

The subjects employed in this investigation were from the inpatient and outpatient services of the Los Angeles CountyUniversity of Southern California Medical Center and were studied at the Clinical Research Center. All studies were performed on euthyroid subjects as determined both by clinical examination and conventional laboratory tests including a protein-bound iodine, triiodothyronine resin uptake, and $24 \mathrm{hr}$ thyroid- ${ }^{181} \mathrm{I}$ uptake.

The dual iodine isotopic method used to measure thyroidal iodine release has been described in detail elsewhere (5). Briefly, the method utilizes ${ }^{12 x}$ I to endogenously label the thyroid gland and thyroxine- ${ }^{181} \mathrm{I}\left(\mathrm{T}_{4}{ }^{-181} \mathrm{I}\right)$ to generate a ${ }^{181}$ I reference source. This ${ }^{181} \mathrm{I}$ reference source acts as an in vivo indicator for the ${ }^{125} \mathrm{I}$ released by the thyroid gland as hormone or iodide. The measurement of ${ }^{225} \mathrm{I} /{ }^{181} \mathrm{I}$ activity in serially-timed urine samples allowed the measurement of the thyroidal iodine release rate relative to past and future urine collections. All release studies were performed during 
what has been termed the "release slope phase" (5). During this phase, the urinary ${ }^{150} \mathrm{I} /{ }^{21} \mathrm{I}$ ratio values were observed to predictably rise in a linear manner when plotted on semilogarithmic coordinates against time. Therefore, a change in the slope during this phase could be interpreted as an alteration in release rate. Serum TSH values were measured by a double antibody radioimmunoassay method (6). The materials for the assay were provided, in part, through the courtesy of the National Pituitary Agency. Assays were performed independently by two of the authors (D.F. and M.A.) without the knowledge of the other's tests results. The TSH value employed in this study was the average of the values from these two laboratories. All samples in a single study were performed in the same assay run in order to eliminate interassay variability. Serum cortisol determinations were performed by the competitive protein-binding assay technique of Nugent and Mayes (7). Estimation of serum thyroxine-binding capacity was determined by a modification of a commercial $T_{3}$ resin uptake test (Triosorb, Abbott Laboratories, North Chicago, I11.) (8). Thyroxine iodine by column and free thyroxine determinations were performed at Bio-Science Laboratories, Van Nuys, Calif. Statistical analysis of the data was performed by conventional paired $t$ test examination The analysis of changes in thyroidal iodine release was performed by comparing the observed changes in values with projected normal values. These projected values were established by interpolation of the release slope between the control periods obtained before and after the testing procedure.

\section{RESULTS}

Studies of increased glucocorticoid levels on TSH and thyroidal iodine release. The administration of pharmacological doses of prednisolone resulted in a prompt and significant $(P<0.01)$ reduction in serum TSH and thyroidal iodine release values. This is graphically illustrated for three euthyroid subjects in Fig. 1. After 3 days of suppression, prednisolone withdrawal resulted in a significant augmentation in TSH and in iodine release values $(P<0.01)$. The augmentation in thyroidal iodine release persisted for several days and was followed by a return to a normal release pattern. For comparison a normal pattern is portrayed in the lower portion of the figure. The TSH results are similar to those recently reported by Wilber and Utiger (4) in euthyroid subjects.

When glucocorticoid administration was continued beyond 3 days, an escape from thyroid suppression was observed as is illustrated in Fig. 2. Increasing the prednisolone dosage from 5 to $20 \mathrm{mg}$ every $8 \mathrm{hr}$ resulted in some further suppression, but the increase did not halt release as was initially observed. During this escape phase, there was a loss of normal diurnal pattern in thyroidal iodine release. A similar lack of a normal diurnal pattern has been observed in four subjects with Cushing's disease secondary to bilateral adrenal hyperplasia. A representative example of a release pattern in Cushing's disease is included in this figure for purposes of comparison. Withdrawal of glucocorticoid administration after prolonged suppression was accompanied by

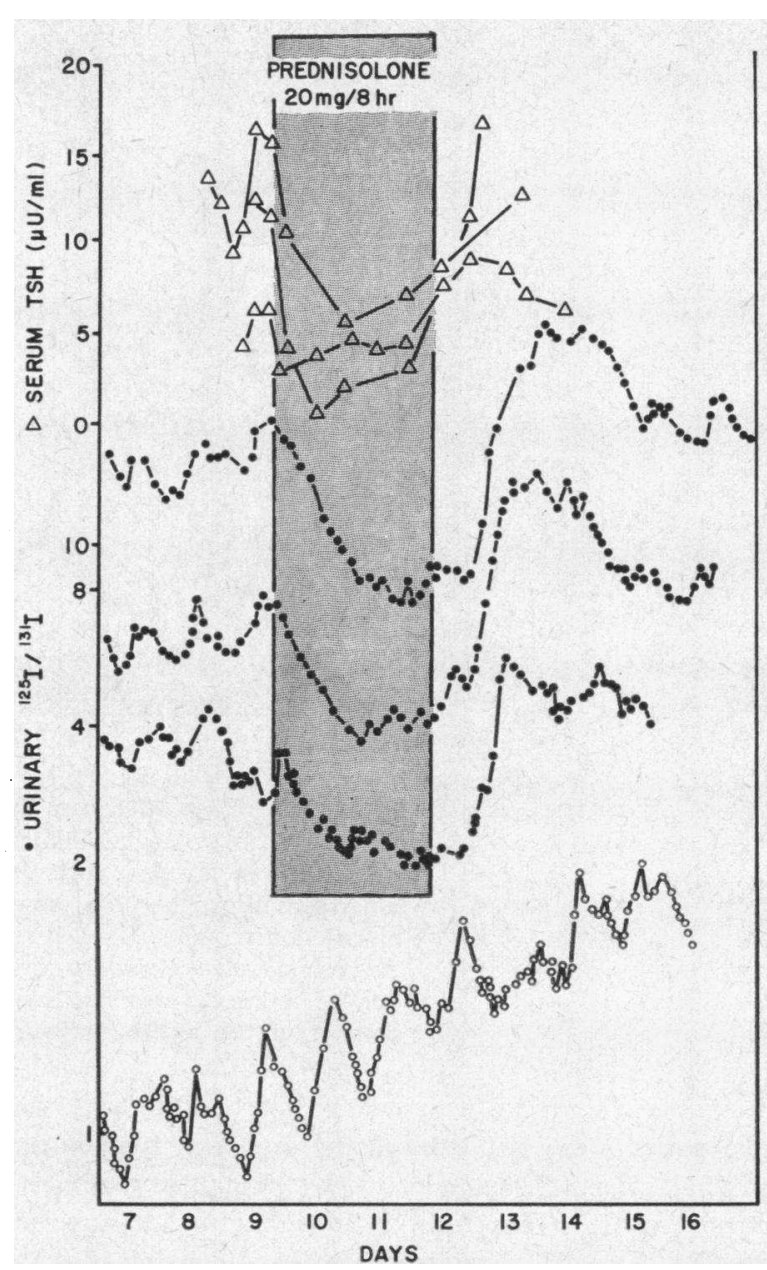

Figure 1 The response of thyroidal iodine release (closed circles) and serum immunoassayable thyrotropin (open triangles) to the administration and withdrawal of pharmacological doses of glucocorticoids in three euthyroid subjects. A normal thyroid release slope is depicted in the lower portion of the figure (open circles).

a prompt rebound in thyroidal iodine release which was again followed in several days by a return to a normal release pattern. Note that the degree and promptness of the initial inhibition of release was greater with $5 \mathrm{mg}$ of prednisolone every $8 \mathrm{hr}$ than with $25 \mu \mathrm{g}$ of triiodothyronine daily.

Studies of hydrocortisone administration on thyroid function in subjects with primary adrenal insufficiency. The withdrawal of maintenance hydrocortisone therapy in two subjects with primary adrenal insufficiency resulted in a gradual rise in both TSH and thyroidal iodine release values. The results on two subjects are illustrated in Fig. 3. Upon resuming maintenance therapy, a prompt and significant drop $(P<0.01)$ in both of these parameters to base line levels was observed. During the with- 


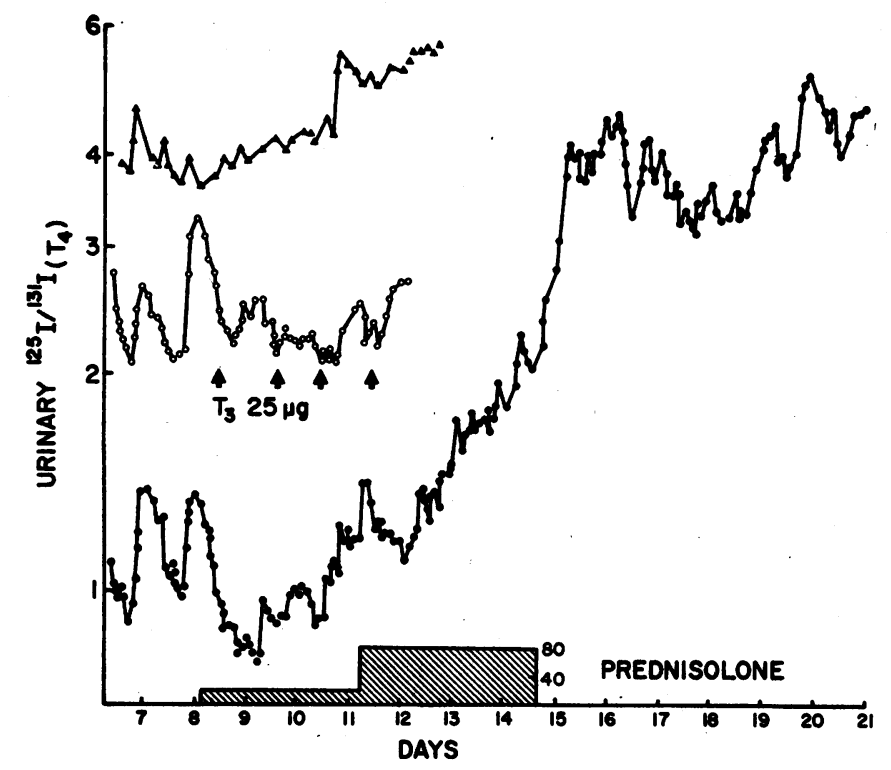

FIGURE 2 The effect of prolonged glucocorticoid suppressive treatment on thyroidal iodine release (closed circles) is depicted in the lower portion of the figure. A repeat study in this same individual illustrates the effects of an incomplete suppressive dose of triiodothyronine $\left(T_{8}\right)$ on thyroidal iodine release (open circles). A typical release pattern in a subject with Cushing's syndrome due to bilateral adrenal hyperplasia is displayed in the upper portion of the figure (closed triangles).

drawal period from maintenance steroid therapy, these two patients did not exhibit any signs or symptoms of adrenal crisis. Serum electrolytes remained within the normal range. Therefore, it is unlikely that any nonspecific "stress" phenomena was responsible for the augmentation in both thyroidal iodine release and TSH levels. Moreover, the induction of hypoglycemia with insulin and cold exposure in one of these subjects failed to alter TSH or thyroidal iodine release values. Note that the periodicity of maintenance hydrocortisone therapy was closely correlated with acute suppression of thyroidal iodine release. The lack of any diurnal fluctuation in thyroidal iodine release was seen in one addisonian subject during the recovery phase after glucocorticoid withdrawal. This may be a reflection of excessive hormonal release which occurred during the glucocorticoid withdrawal phase and now exerts an inhibitory action on hypothalamic-pituitary centers after the resumption of maintenance steroid therapy. Similar findings on release studies have been observed in three other addisonian subjets not illustrated in Fig. 3; thus this response to cortisol withdrawal appears to be a reproducible phenomenon.

Studies of the spontaneous diurnal rhythm of serum TSH, plasma cortisol, and thyroidal iodine release. Fig. 4 illustrates the spontaneous diurnal rhythm of serum
TSH, serum cortisol, and thyroidal iodine release measured simultaneously in three euthyroid subjects. During the midday hours, all three parameters were observed to fall in a parallel manner. When serum cortisol levels fell to their lowest values during the late evening, there was a rise both in TSH and in iodine release. In the early morning hours when cortisol values were rapidly rising, a drop in TSH and in iodine release was observed. These three subjects were selected from a much larger group of euthyroid individuals studied in a similar manner. Unfortunately, most of the euthyroid subjects studied had serum TSH values which were close to or below the limit of sensitivity of the TSH immunoassay. Comparison of the diurnal rhythm of serum cortisol and thyroidal iodine release in 10 such subjects is summarized in Fig. 5. A similar reciprocal relationship between the zenith and nadir values of serum cortisol and release determinations was observed in these subjects, but again during the midday hours, these two parameters were observed to fall in a parallel manner.

Direct effect of glucocorticoids on thyroidal iodine release and thyroxine-binding globulin values. Glucocorticoids may exert an independent inhibitory action on thyroid function by a direct action on the thyroid gland. To rule out this possibility a euthyroid subject was administered a full inhibitory dose of triiodothyronine 
which was followed by daily intramuscular injections of $1 \mathrm{U}$ of bovine TSH (Armour \& Co., Chicago, Ill., Thyrtropar). This exogenous TSH stimulation resulted in a series of reproducible stimulatory patterns in thyroidal iodine release. As can be observed in Fig. 6, the administration of prednisolone did not alter the release pattern thus indicating no direct action of glucocorticoid on altering the response of the thyroid gland to $\mathrm{TSH}$. No significant change $(P>0.5)$ in thyroxine-binding globulin values was noted in 20 timed matched samples taken $24 \mathrm{hr}$ before and after prednisolone administration. The mean values were $24 \pm 5 \mu \mathrm{g} / 100 \mathrm{ml}$ ( $\pm \mathrm{SD}$ ) before and $23 \pm 6 \mu \mathrm{g} / 100 \mathrm{ml}$ after prednisolone administration. Therefore, changes in thyroxine-binding globulin did not account indirectly for the acute suppression of TSH values observed.

Rebound of thyroidal iodine release after glucocorticoid withdrawal as a measure of $T S H$ reserve. The augmentation in thyroidal iodine release values after glucocorticoid withdrawal might provide an effective method for indirectly assessing the adequacy of pituitary TSH as well as hypothalamic thyrotropin-releasing factor (TRF) reserve capacity. Fig. 7 displays the release patterns in an acromegalic subject before and 6 months

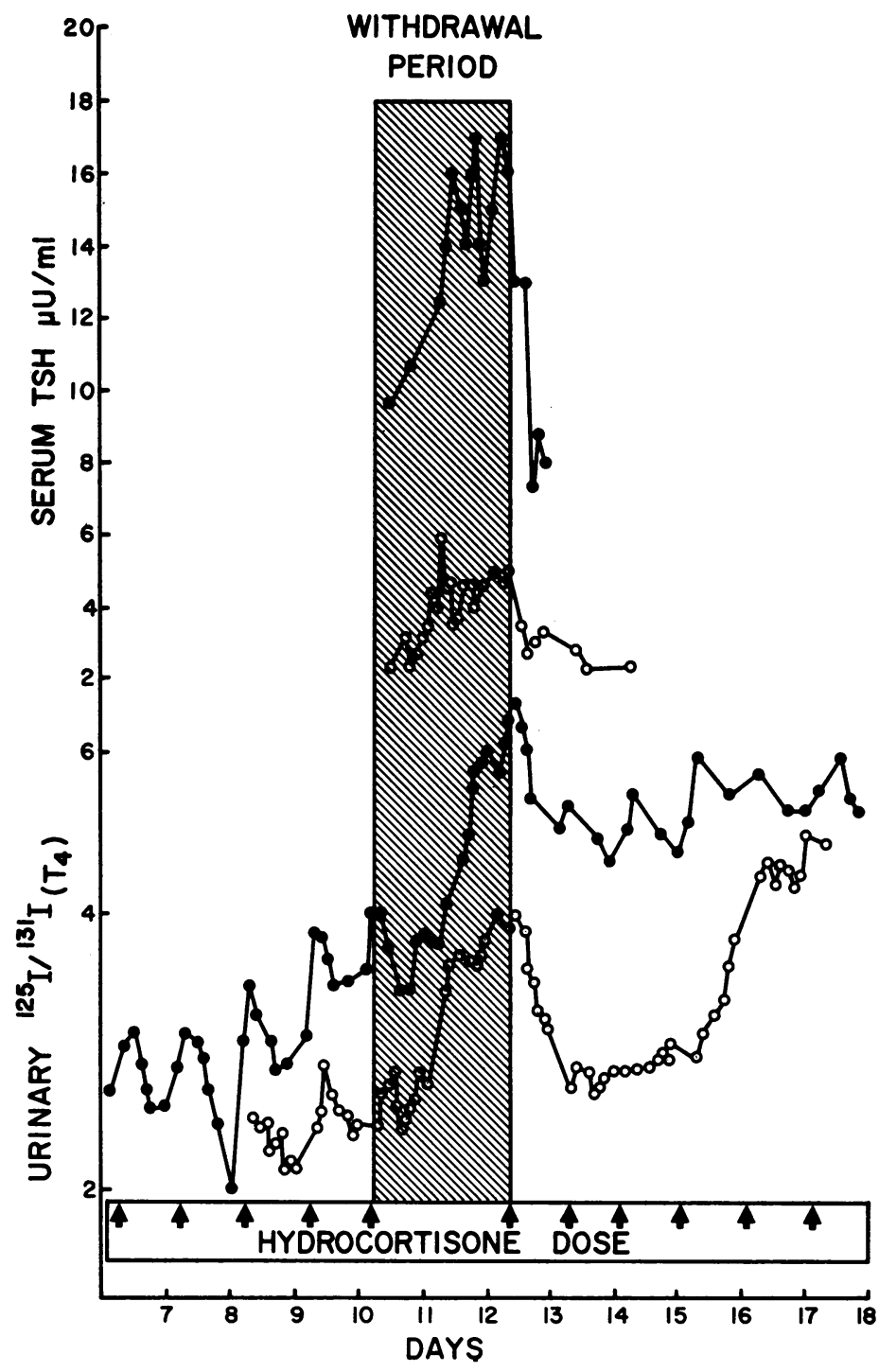

FIGURE 3 The effects of withdrawal and reinstitution of maintenance hydrocortisone therapy on urinary thyroid release patterns and on serum immunoassayable TSH values in two euthyroid subjects with primary adrenal insufficiency. 


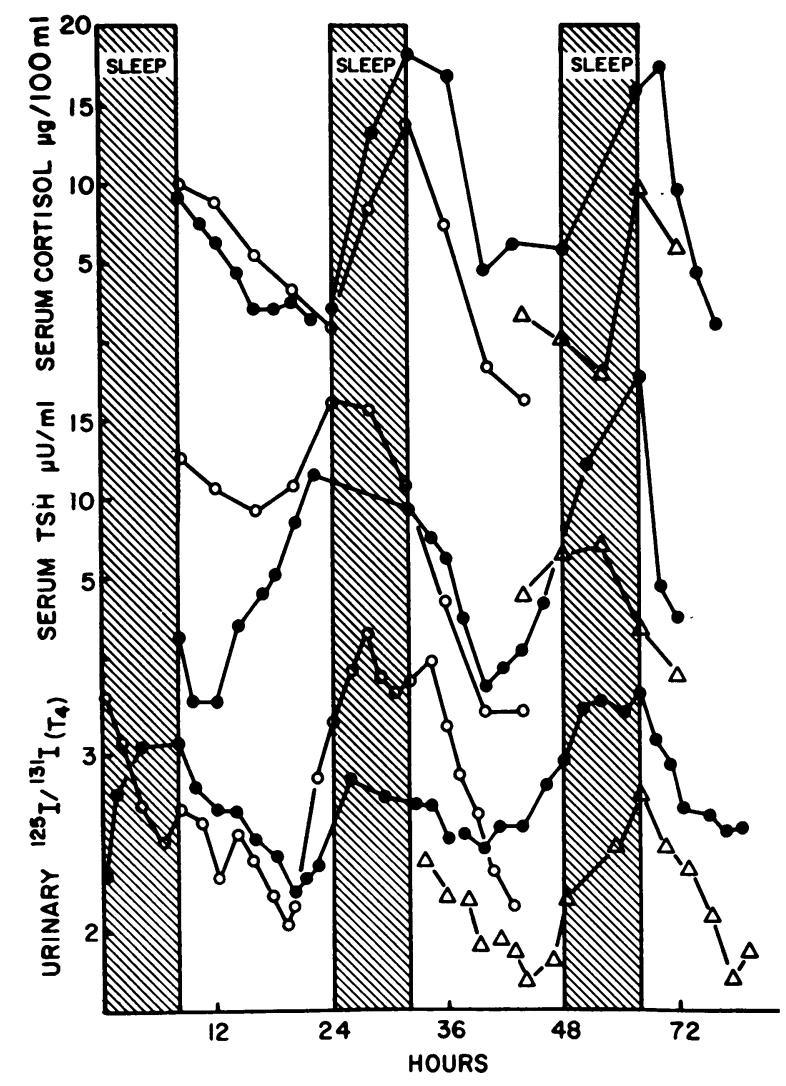

FIgURE 4 The spontaneous diurnal rhythms of serum TSH, cortisol, and urinary thyroidal iodine release are shown in three euthyroid subjects.

after cryohypophysectomy. The preoperative release pattern was similar to that observed in normal subjects as illustrated in Fig. 1. Unfortunately, serum TSH values were at or below the level of sensitivity of this assay, therefore not allowing this parameter to be employed in this study. Preoperative pituitary function tests indicated adequate pituitary function. Urinary gonadotropins were between 6 and 50 mouse units per $24 \mathrm{hr}$, and the base line urinary ketogenic steroid value was $18.3 \mathrm{mg}$ rising with metapyrone stimulation to $52.4 \mathrm{mg} / 24 \mathrm{hr}$. After cryohypophysectomy, a marked amelioration in the acromegalic features of this patient was noted. This amelioration corresponded with a drop in serum growth hormone levels of from $11.2 \mathrm{~m} \mu \mathrm{g} / \mathrm{ml}$ preoperatively to $1.0 \mathrm{~m} \mu \mathrm{g} / \mathrm{ml}$ postoperatively. Urinary ketogenic steroid excretion values fell to $3.9 \mathrm{mg} / 24 \mathrm{hr}$ and were $4.7 \mathrm{mg} / 24$ $\mathrm{hr}$ after metapyrone administration ,and 24-hr urinary gonadotropin levels became undetectable. In spite of the laboratory evidence of markedly impaired pituitary function, routine thyroid function tests remained essentially unchanged. Preoperatively, the protein-bound iodine
(PBI) was $6.9 \mu \mathrm{g} / 100 \mathrm{ml}$, the $24 \mathrm{hr}$ thyroid ${ }^{-131} \mathrm{I}$ uptake was $10 \%$, and the $\mathrm{T}_{3}$ resin uptake was $12 \%$ (normal values: $10.3-14.3 \%$ ); and postoperatively, the PBI was $7.1 \mathrm{\mu g} / 100 \mathrm{ml}$, the ${ }^{131} \mathrm{I} 24 \mathrm{hr}$ thyroid uptake test was $11 \%$, and the $\mathrm{T}_{3}$ resin uptake value was $13.2 \%$. The thyroxine iodine by column value was $6.4 \mu \mathrm{g} / 100 \mathrm{ml}$ (normal values: $2.9-6.4 \mu \mathrm{g} / 100 \mathrm{ml}$ ) and the "free" thyroxine determination was $1.8 \mathrm{~m} \mu \mathrm{g} / 100 \mathrm{ml}$ (normal values: 1.1 $2.2 \mathrm{~m} \mu \mathrm{g} / 100 \mathrm{ml}$ ) postoperatively. The postoperative thyroidal iodine release pattern was essentially identical to that of the preoperative pattern until prednisolone withdrawal occurred. The release values after glucocorticoid withdrawal were observed to gradually rise so as to eventually reestablished a release slope similar to that observed preoperatively. This indicated that enough TSH was being released to maintain normal thyroid function. But the sluggish rise in the release curve and the complete loss of an overshoot as seen in the preoperative study very likely revealed an impaired TSH reserve capacity.

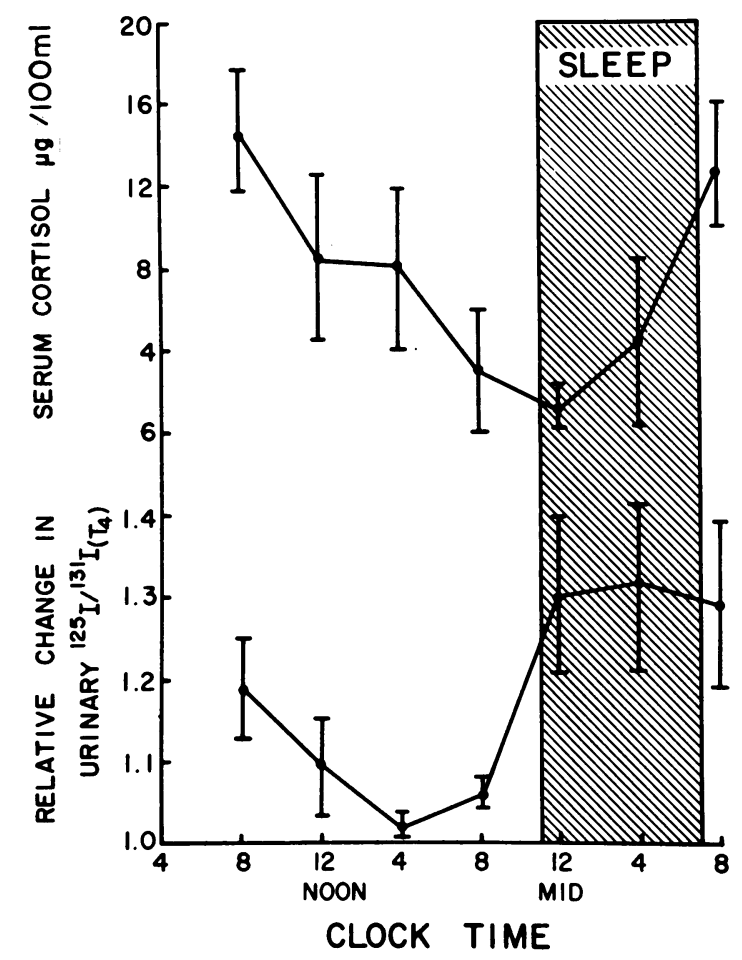

FIgURE 5 The composite diurnal pattern of serum cortisol and urinary thyroidal iodine release are illustrated in 10 euthyroid subjects. The vertical bar incorporates $1 \mathrm{SD}$ from the mean value. The urinary iodine release values were normalized so that 1.0 represented the lowest ${ }^{125} \mathrm{I} /{ }^{131} \mathrm{I}\left(\mathrm{T}_{4}\right)$ ratio value during the $24 \mathrm{hr}$ period that was studied. The higher 8:00 a.m. urinary ratio value, observed on the 2 nd day, reflects the normal rising release slope pattern. 


\section{DISCUSSION}

The evidence presented in this study clearly supports the concept that glucocorticoids are capable of acutely inhibiting thyroid function. This action most likely occurs by inhibition of secretion of TRF by the hypothalamus. This conclusion is based on the following observations: (a) glucocorticoids fail to directly alter release from the thyroid gland stimulated by exogenous TSH; $(b)$ no acute changes in thyroxine-binding globulin values occur with glucocorticoid administration; (c) glucocorticoids do not alter peripheral thyroxine turnover rates $(9)$; and $(d)$ glucocorticoids do not inhibit the action of TRF directly on the pituitary gland of the rat (4). The finding that glucocorticoids can produce complete inhibition of thyroidal iodine release suggests that the acute regulation of TSH release is primarily by TRF (10).

The glucocorticoid inhibition appeared to be of a transient nature. After 2 or 3 days of glucocorticoid suppression, escape of thyroidal iodine release occurred. This escape phase of glucocorticoid suppression appeared to be fairly complete as judged by the steepness of the release slope. In contrast to the normal release pattern, no diurnal fluctuation in thyroid activity was evident. Moreover, after $1 \mathrm{wk}$ of glucocorticoid administration, withdrawal resulted in a transient augmentation of release over the

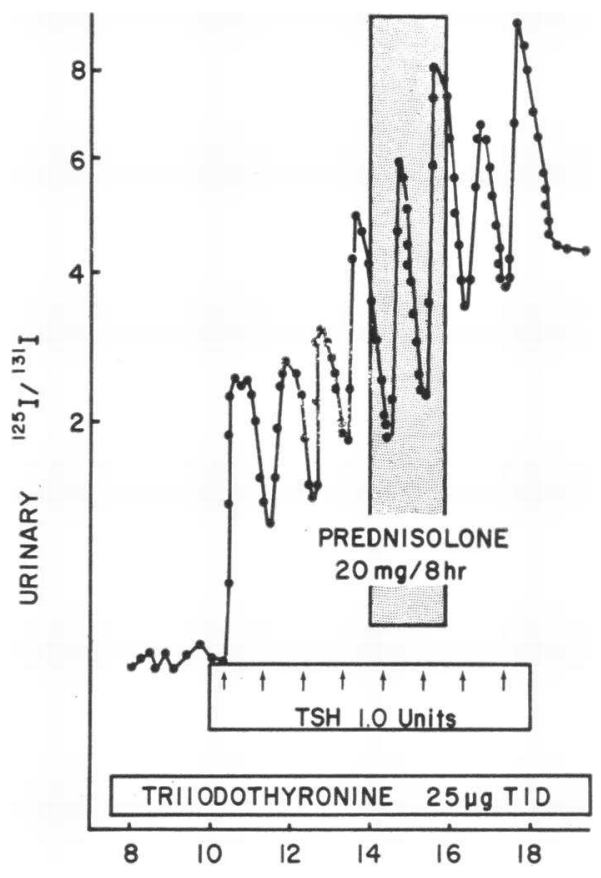

Figure. 6 The failure of glucocorticoids to directly inhibit the action of bovine TSH on the thyroidal iodine release is depicted. The arrows indicate the timing of the bovine TSH injections.

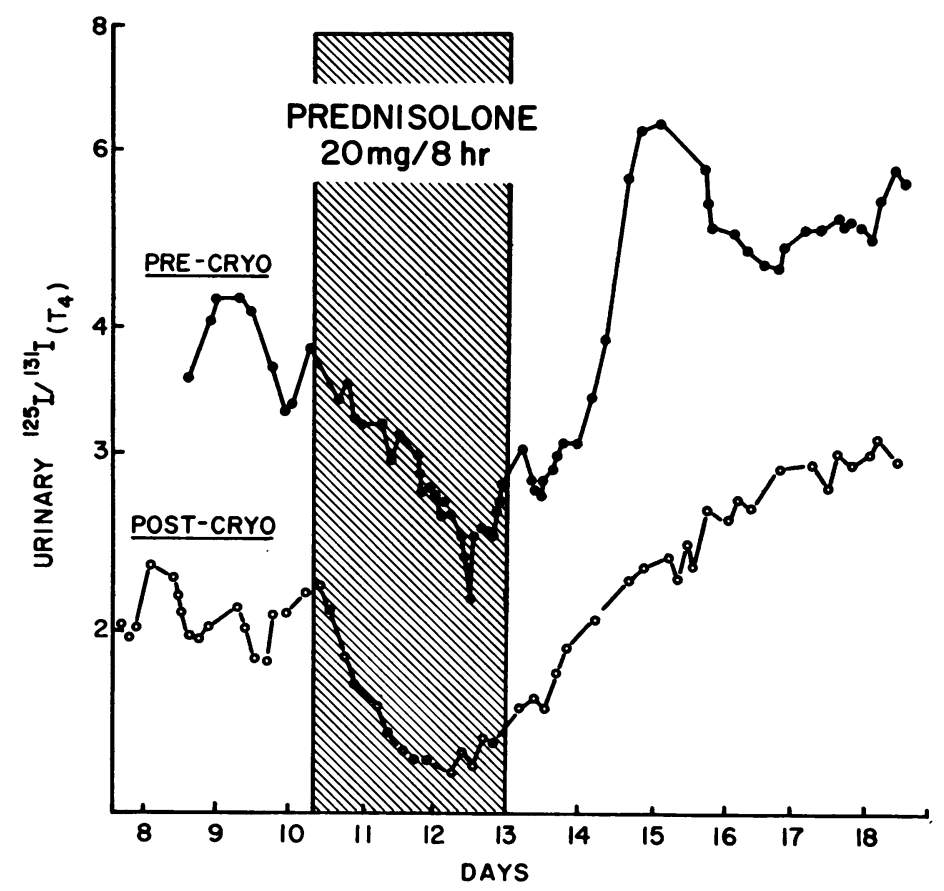

FIGURE 7 A study of the rebound response after glucocorticoid withdrawal in an acromegalic subject pre- and postcryohypophysectomy. The slow rise in urinary ratio values and in the absence of an overshoot response during days 14 and 15 indicated a probable impairment of thyrotropin reserve capacity. 
next 3-4 day period. Similar results have been observed in other subjects in whom glucocorticoid administration had been carried over a period of $3 \mathrm{wk}$. These latter observations are compatible with the concept that glucocorticoids may exert a prolonged tonic suppression but not complete inhibition of $\mathrm{TSH}$ release.

The most likely cause for the spontaneous daily surge in thyroidal iodine release characteristic of the euthyroid subject was a diurnal variation in serum $\mathrm{TSH}$ secretion which, in turn, was triggered by spontaneous variations in the circulating hydrocortisone levels. This hypothesis is supported by the following findings: $(a)$ there was an inverse correlation between glucocorticoid administration and $\mathrm{TSH}$ and, in turn, thyroidal iodine release activity both in normal and addisonian patients; $(b)$ the daily cyclicity of base line thyroidal iodine release determinations in the addisonian patient appeared to correlate with the timing of maintenance hydrocortisone administration; (c) abolishment of the cyclicity of thyroidal iodine release was produced by pharmacological doses of glucocorticoids; $(d)$ there was a spontaneous loss of diurnal cyclicity in subjects with Cushing's disease; and (e) the spontaneous diurnal rhythm of serum $\mathrm{TSH}$, plasma cortisol, and thyroidal iodine release activity in euthyroid subjects revealed a reciprocal relationship between the zenith and the nadir values of circulating cortisol and TSH and/or thyroid release. Early observations by Odell, Wilber, and Utiger (6) indicated that no diurnal variation in $\mathrm{TSH}$ values appeared to occur in euthyroid man. In contrast to these workers, LemarchandBeraud and Vannotti (11) and Blum, Greenspan, and Magnum (12) have observed a diurnal trend in serum immunoassayable TSH values similar to what we have observed. The most logical explanation for this discrepancy is that the affinity of the presently available human TSH antisera does not allow precise discrimination of $\mathrm{TSH}$ levels in the low euthyroid range. In addition, spontaneous diurnal variations in either pituitary and/or serum $\mathrm{TSH}$ determinations have been found to occur in laboratory animals $(2,3,13)$.

Although it its apparent that fluctuations in hydrocortisone levels constitute the best explanation for the spontaneous cyclicity in thyroidal iodine release, it was also noteworthy that an inverse correlation between serum cortisol and TSH secretion was not always present. As illustrated in Figs. 4 and 5, the midday serum cortisol, TSH, and thyroidal iodine release patterns declined in a parallel manner. It is only when serum cortisol values approached low levels that the augmentation in thyroid activity occurred. In addition, some surging of thyroidal iodine release activity was noted in the addisonian patients during the period of hydrocortisone withdrawal. Moreover, a similar effect was noted in some euthyroid patients on large doses of exogenous gluco- corticoids. These findings indicate that other influences may be operative in regulating the diurnal variation in $\mathrm{TSH}$ release other than hydrocortisone levels alone. Therefore, there is the distinct possibility that an intrinsic hypothalamic surging mechanism for TRF release may exist at least partially independent of the feedback influences of circulating hydrocortisone. Further work is in progress in an attempt to clarify this problem.

Wilber and Utiger have speculated that the rebound in TSH levels after glucocorticoid withdrawal might prove to be a useful tool in the assessment of $\mathrm{TSH}$ reserve capacity in man (4). Unfortunately, the presently available immunoassay for $\mathrm{TSH}$ does not allow the valid measurement of TSH concentrations in many normal subjects and certainly not in patients with varying degrees of hypopituitarism. In contrast, the measurement of thyroidal iodine release rates, employing the dual isotopic method (5) does not suffer from this technical limitation. The acromegalic patient studied before and after cryohypophysectomy clearly showed an impairment of a rebound response in release following glucocorticoid withdrawal after cryohypophysectomy in spite of a failure of the routine thyroid function tests to demonstrate any change. A study of release patterns after glucocorticoid withdrawal in subjects with varying degrees of pituitary impairment will be the central theme of a study to be published from this laboratory in the near future.

It seems clear that thyroid function in man can be regulated by stimuli other than the circulating levels of thyroid hormone. In addition to glucocorticoids, other steroid hormones may affect thyroid glandular function (14). Further, various stimuli, such as surgery (15), birth (16), and prolonged exercise (17), may produce significant alterations in thyroid function in man. It is now apparent that the newer methods for appraising thyroid activity, such as immunoassayable TSH levels and the dual iodine thyroidal iodine release method, allows a more critcial insight into factors which may influence the hypothalamic-pituitary-thyroid axis.

\section{ACKNOWLEDGMENTS}

We wish to express our gratitude to Miss Evangelyn Wise and Mr. Dwight W. Warren for their excellent technical assistance and to Mrs. Anne Santo for assistance in preparing the manuscript.

This study was supported, in part, by U. S. Public Health Service Grant No. AM 11727 and General Clinical Research Center Grant No. RR-43.

\section{REFERENCES}

1. Ingbar, S. H., and N. Freinkel. 1956. ACTH, cortisone and the metabolism of iodine. Metab. (Clin. Exp.) 5:652.

2. Ducommun, P., E. Sakiz, and R. Guillemin. 1966. Dissociation of the acute secretions of thyrotropin and adrenocorticotropin. Amer. J. Physiol. 210: 1257. 
3. Retiene, K., E. Zimmerman, W. J. Schindler, J. Neuenschwander, and H. S. Lipscomb. 1968. A correlative study of endocrine rhythms in rats. Acta Endocrinol. 57: 615 .

4. Wilber, J. F., and R. D. Utiger. 1969. The effect of glucocorticoids on thyrotropin secretion. J. Clin. Invest. 48: 2096.

5. Nicoloff, J. T. 1970. A new method for the measurement of thyroidal iodine release in man. J. Clin. Inc'est. 49: 1912.

6. Odell, W. D., J. F. Wilber, and R. D. Utiger. 1967. Studies of thyrotropin physiology by means of radioimmunoassay. Recent Progr. Hormone Res. 23: 47.

7. Nugent, C. A., and D. M. Mayes. 1966. Plasma corticosteroids determined by use of corticosteroid-binding globulin and dextran-coated charcoal. J. Clin. Endocrinol. Mctab. 26: 1116.

8. Nicoloff, J. T., H. A. Gross, D. W. Warren, J. H. Mestman, and G. V. Anderson. 1970. Thyroxine-binding globulin values as a measure of placental adequacy. Obstet. Gynecol. 35: 191.

9. Ingbar, S. H., and N. Freinkel. 1955. The influence of $\mathrm{ACTH}$, cortisone and hydrocortisone on the distribution and peripheral metabolism of thyroxine. J. Clin. Inv'est. $34: 1375$.
10. Purves, H. D. 1964. Control of thyroid function. In The Thyroid Gland. R. Pitt-Rivers and W. R. Trotter, editors. Butterworth \& Co. Ltd. London. 2: 1.

11. Lemarchand-Béraud, Th., and A. Vannotti. 1969. Relationships between blood thyrotrophin level, protein bound iodine and free thyroxine concentration in man under normal physiological conditions. Acta Endocrinol. $60: 315$.

12. Blum, A. S., F. S. Greenspan, and J. Magnum. 1968. Circadian rhythm of serum TSH in normal human subjects. Exerpta Med. Int. Congr. Ser. No. 157. (Abstr. 34).

13. Bakke, J. L., and N. Lawrence. 1965. Circadian periodicity in thyroid stimulating hormone titer in rat hypophysis and serum. Metab. (Clin. Exp.) 14: 841

14. Gross, H. A., M. D. Appleman, and J. T. Nicoloff. 1970. Acute inhibition of thyroid release (TR) by estradiol. Clin. Res. 28: 121. (Abstr.)

15. Nicoloff, J. T., and E. R. Weiss. 1968. Effect of thyroid and non-thyroid surgery on thyroidal iodide release in man. Clin. Res. 16: 273. (Abstr.)

16. Fisher, D. A., and W. D. Odell. 1969. Acute release of thyrotropin in the newborn. J. Clin. Invest. 48: 1670.

17. Irvine, C. H. G. 1968. Effect of exercise on thyroxine degradation in athletes and non-athletes. J. Clin. Endocrinol. Metab. 28: 942 . 